\title{
RISCOS OCUPACIONAIS EM UTI: PROTEÇÃO ESPECÍFICA*
}

\author{
Maria da Natividade Abreu da Costa** \\ Irene Alves de Deus***
}

\begin{abstract}
RESUMO - Aponta os riscos ocupacionais que a equipe multiprofissional se expõe diariamente. Na tentativa de minimizar os riscos existentes são traçadas medidas de proteção especifica que se estendem desde a planta física ao preparo técnico dos funcionários. São utilizadas como variáveis o trinômio ambiente/paciente/equipe de enfermagem, relacionando assim os riscos e a proteção especifica.
\end{abstract}

\begin{abstract}
Reflect about occupational risks that the multiprofisssional team exposes herself daily. In attempt to minimizing the existentes risks they has traced specific protection measures that to extend since physics plant to staff technique preparation of the employee. They has utilized as variables the enviroment/patient/nursing team trinomial, relating thus the risks and specific protection.
\end{abstract}

\section{INTRODUÇÃO}

O crescente interesse representado na classe dos enfermeiros para os aspectos de riscos nas Unidades de Internação fez-nos refletir de maneira especial sobre a Unidade de Terapia Intensiva.

As infecções em UTI representam nos dias atuais. um grave problema, onde o ambiente, a equipe e o paciente constituem a grande fonte de infecção. Preocupadas com esta problemática, nos propomos a trabalhar os riscos ocupacionais e traçar as medidas de proteção específicas destes em UTI.

Acreditamos que o exercício institucional da equipe multiprofissional na referida unidade desenvolve-se obrigatória e permanentemente num ambiente insalubre, visto que é fortuita a invasão de agentes biológicos agressivos, não esquecendo o uso de agentes químicos cada vez mais potentes e, portanto, mais tóxicos diante da flora bacteriana progressivamente resistente. Isto forma um ciclo vicioso onde o ambiente, o cliente e os profissionais agridem e podem ser agredidos.

Relataremos a experiência por nós vivenciada na Unidade de Terapia Intensiva de um Hospital do Nordeste na tentativa de minimizar os riscos ocupacionais existentes, interrelacionando o trinômio ambiente/paciente e equipe intensivista.

\section{OBJETIVOS}

Relatar a experiência vivenciada pelas autoras no que diz respeito aos riscos em UTI e a implementação de ações visando a sua redução.

Relacionar as medidas de proteção específica contra os riscos ocupacionais e o controle de infecção hospitalar.

\section{REVISÃO BIBLIOGRÁFICA}

A Unidade de Terapia Intensiva é considerada uma área crítica do hospital, devido a características próprias que possue, onde vários fatores contribuem no sentido de tornar cada vez mais o ambiente insalubre, gerando riscos ocupacionais e conseqüentemente infecção hospitalar. O enfermeiro intensivista tem papel fundamental no sentido de promover um ambiente seguro e terapêutico.

ELHART (1983) afirma que “a segurança dos doentes e do pessoal do serviço de saúde constitue atribuição e responsabilidade de todo o enfermeiro. Embora a tecnologia e as experiências estejam em constante progresso, possibilitando cada vez mais uma assistência segura e humana a todos os doentes, as imposições da lei e as queixas do cliente continuam a demonstrar que a assistência ideal, ou pelo menos satisfatória, nem sempre é conseguida. Uma das responsabilidades que cabem ao enfermeiro é a de avaliar, modificar e fomentar um ambiente seguro, em que seja possível dispensar cuidados o mais próximos possível da perfeição".

CANSIAN (1977) diz que "o aparecimento da infecção é determinado pela interação de agentes mórbidos com o meio ambiente e o homem. No hospital, asprincipais fontes de infecão decorrem: do paciente, visitante, pessoal, equipamentos, técnicos de trabalho e planta fisica".

SANTOS (1980) afirma que "um dos setores hospitalares a enfrentar de maneira muito especial o problema da infecção é a Unidade de Terapia Intensiva por ser o local onde são assistidos os pacientes 'críticos', altamente expostos a riscos de infeç̧ão. Em geral na UTI, há uma aglomeração muito grande de todo tipo de equipamento e pessoal e, pela sua própria natureza, nelas são desenvolvidas muitas atividades. Por outro lado, os pacientes que para lá são levados, encontram-se em estado grave e correm riscos de vida, por isso, estão mais expostos a contrair infecção no hospital e até mesmo um número pequeno de microorganismo de virulência relativamente baixa, poderão produzir infecções oportunistas de efeitos danosos".

Dentre os fatores relacionados ao tipo de paciente interligamos os procedimentos críticos freqüentes nesta unidade.

SANTOS (1980) informa que "o grau de aglomeração e a freqüência com que são realizados os procedimentos de urgência como traqueostomia, ressusci-

\footnotetext{
* Trabalho Classificado em 1ํo lugar-Prêmio ARIADNE LOPES DE MENEZES - 40 CBEn-Belém

** Diretora da Divisão de Enfermagem do Hospital Governador João Alves Filho - Autora

*** Supervisora de Enfermagem da Unidade de Terapia Intensiva do Hospital Governador João Alves Filho
} 
tação cardíaca, flebotomia e outros, e a pressão que geralmente acompanha essas técnicas, combinam-se para tornar a UTI, uma das áreas mais contaminadas do hospital".

FREITAS (1987) diz que "a UTI, é um dos setores do hos pital que enfrenta de maneira especial o problema da infecção respiratória. Os pacientes são considerados críticos, altamente expostos aos riscos de infecção. É necessário protegê-los permanentemente através de técnicas adequadas, reciclagem constantes da equipe de enfermagem. A enfermagem deve conhecer todas as normas e procedimentos necessários para a prevenção e controle de infecção".

Outro fator cruciante na infecção hospitalar com aumento de resistência ambiental e humana é o uso indiscriminado de antibioticoterapia.

KFOURI (1985) afirma que "uma forma valiosa para influenciar uma estratégia do uso racional de antibiótico, segundo a OMS, é obter informações retrospectivàs sobre o consumo de antibióticos, estimulando uma discussão entre o corpo clínico e a CCIH, principalmente pela freqüencia dos casos de infecção e dos coeficientes de sensibilidade e resistência locais dos germes isolados.

Assim a antibioticoterapia deve basear-se em diagnóstico clínico preciso da natureza do processo infeccioso. Isto está diretamente relacionado com a identificação do agente patogênico através de cultura microbiológica; ou, quando isto não for praticável inferindo o estilo e a natureza da infecção".

Observando as características peculiares da UTI, existem várias estratégias que poderão ser utilizadas para tornar esta unidade um ambiente menos insalubre como relata os autores abaixo.

SIL VA (1982) diz que "em Centro Cirúrgico o revestimento das paredes e teto precisa ser de material resistente, liso, lavável, a fim de facilitar a limpeza e a manutenção". Por analogia adaptamos esta afirmação a Unidade de Terapia Intensiva.

LOL A (1984) citando Beland afirma que " $a$ temperatura essencial ao conforto e aquela em torno de $21^{\circ} \mathrm{C}$ a fim de não criar obstáculos às funções normais $e$ que segundo Prince à temperatura de $20^{\circ}$ a $23^{\circ} \mathrm{C}$ pode ser a melhor adaptada para a maioria das pessoas". Afirmando ainda que as temperaturas acima de $27^{\circ} \mathrm{C}$ podem conduzir o homem ao calor excessivo, diminuindo-lhe as energias naturais, aumentando a sudorese e predispondo-lhe a uma sensibilidade anormal ao frio.

O Ministério da Saúde (Brasil, 1985) considera a UTI como uma unidade crítica e como tal "deverá utilizar para desinfecção do ambiente o fenol sintético". Diz ainda que "é conveniente substituir a higiene das mãos com sabão pela anti-sepsia com solução detergente anti-séptica. A anti-sepsia requer agentes germicidas capazes de inibir ou de mutar microorgarismo sem provocar irritação ou sensibilização local após repetidas aplicações. Os mais adt auados são as soluçães aquosas de pvpi a 10\% (1\% de Iodo Livre), clorohexidina a $4 \%$ ou hexaclorofeno a 3\%".

SANTOS (1980) relata que "o lixo deve ser coletado em recipiente próprio, revestido de saco plástico impermeável, que possa ser fechado hermeticamente, de modo que ao ser desprezado não derrame. A retirada do lixo é feita com freqüência, isto é, à medida em que o recepiente esteja cheio e em casos especiais (materiais contaminados, odor fétido, etc.").
Afirma ainda que "os utensílios (comadres, compadres, bacias, etc.) devem ser de uso individual, desde admissão do paciente até sua alta. Após o uso devem ser desinfectados com solução apropriada, lavados com água corrente e enxugados Recomenda-se a sua esterilização pelo menos uma vez por semana".

CANSIAN (1977) afirma que o pessoal de trabalho deve permanecer em boa situação de saúde, uma vez que está sujeito a transmitir inf ecção aos pacientes e a contaminar o ambiente de trabalho, bem como a contrair inf ecção.

$O$ aparecimento de muitos casos de infecção por um mesmo microorganismo exige investigações entre o pessoal profissional e não profissional, relacionando com os cuidados dos pacientes, pois poderá existir um portador são entre eles". Continua ressaltando " $a \mathrm{im}$ portância do uso adequado dos uniformes e vestuários evitando a disseminação de germe ao hospital'.

ELHART (1983) afirma que "o doente que sofra de qualquer doença contagiosa deverá estar separado dos restantes que não sofram dessa doença. Devem fazer-se todo o possível para que os organismos se limitem às suas áreas de contaminações".

$\mathrm{O}$ enf ermeiro na sua unidade funciona como um líder, logo executa além das funções assistencial a de educador, tanto para o paciente como para toda a equipe intensivista tendo como objetivo a assistência adequada baseada nos seus conhecimentos científicos.

ELHART (1983) relata que "embora grande parte do trabalho de limpeza seja, na realidade, executado por outro pessoal, é ao enfermeiro que cabe verificar a aplicação dos princípios essenciais, devendo ele próprio aplicá-los sempre que julgue necessário, ou detectar qualquer prática que seja pouco segura ou ine ficaz na prevenção contra o alastramento de microorganismos patogênicos. É o enfermeiro quem deve controlar e regular o ambiente físico que rodeia $o$ doente".

CASTRO (1988) diz que "a programação de um curso de treinamento para equipe de enfermagem do C.T.I. visa a formação de novos hábitos, através da reciclagem de conhecimentos, fornecendo, ao funcionário, maior segurança e com isto assegurando ao paciente melhoria de atendimento, através das técnicas específicas e tratamento intensivo".

EL HART (1983) afirma que "todo o profissional de enfermagem se vê perante um fluxo cada vez mais intenso de dados que exigem capacidade de decisão, para satisfação das carências do doente. Uma vez que essas carências se alteram constantemente, o enfermeiro vê-se obrigado a variar as suas decisões e adaptálas a essas alterações, à medida que novas informações vão sendo colhidas para processamento. Para poder utilizar essas informações e chegar a conclusões válidas, o enfermeiro tem de saber formular ou compreender os princípios científicos genéricos que norteiam os cuidados de saúde, raciocinar com base nestas leis e princípios e orientar a sua ação de acordo com eles".

Ao plane jar o seu esquema de cuidados a dispensar ao doente, o enf ermeiro deverá ter como diretriz a compreensão do princípio científico que diz que "todo o comportamento tem uma determinada finalidade".

\section{METODOLOGIA, APRESENTAÇÃO E ANÁLISE DOS RESULTADOS}

Este estudo foi realizado em uma Unidade de 
Terapia Intensiva de um Hospital Estadual de Pronto Socorro, recém-inaugurado do Nordeste. Esta é constituída de sete leitos, sendo especificamente um de isolamento e um infantil. Pertence a equipe intensivista: médicos plantonistas, diaristas especialistas, fisioterapeutas, nutricionistas, supervisora de enfermagem, enfermeiras assistenciais, auxiliares de enfermagem, atendentes, of icial administrativo e zeladoras.

Embora os componentes tenham sido admitidos pós-concurso, encontramos vários riscos gerados por hábitos e conhecimento ou até mesmo desconhecimento de cada um frente a assistência a paciente crítico. Aplicamos um questionário a todos os funcionários de enfermagem com fins de avaliar o conhecimento e conseqüentemente descobrir o grau de risco existente. Paralelamente, avaliávamos a execução dos procedimentos e realizávamos reuniões periódicas com toda a equipe.

Com relação a planta física detectamos os riscos através da observação in locus dias antes do funcionamento da Unidade e posteriormente foram reforçados pela realização cotidiana da assistência ao paciente crítico, que era dificultada por determinadas falhas existentes já detectadas anteriormente por nós. Com a utilização dos métodos específicos de proteção vimos que os riscos ocupacionais existentes estavam ligados diretamente aos riscos dos pacientes e que toda estratégia montada agiu efetivamente tanto no paciente quanto na equipe intensivista, tendo como ef eito principal a redução da infecção hospitalar.

A avaliação inicial da planta foi feita no período de um mês anterior ao funcionamento da unidade. E durante os três primeiros meses de funcionamento realizamos avaliação da atuação da equipe intensivista através da observação no desempenho das suas atividades e aplicação do questionário à equipe de enfermagem, em seguida executamos o nosso plane jamento geral de atuação com posterior implementações.

Discutiremos a seguir os riscos detectados relacionando com as medidas específicas traçadas.

Através da observção da área física detectamos várias falhas que contribuia para o aumento do índice de infecção em nossa unidade tais como: paredes e tetos revestidos de material não lavável, em especial o teto de gesso; o termostato sem controle real ocorrendo mudanças bruscas de temperatura; presença de vetores no ambiente devido a localização baixa do hospital; uso indiscriminado de antibiótico disseminando aerodispensóides químicos cada vez mais potentes na unidade; cruzamento de pacientes contaminados, ou seja, a admissão de paciente no isolamento era feita pela área central da UTI; painéis dos boxes com diversas saídas com difícil aceso para limpeza; o não acondicionamento adequado do lixo pelas zeladoras da unidade; e a inexistência de área específica para o pessoal de enfermagem descansar o que faziam no chão do vestiário.

Partindo destas observações acionamos o serviço de manutenção no sentido de resolver os problemas detectados onde realizamos: pintura das paredes e teto com tinta impermeabilizante; adequação do termostato entre 20 e $21^{\circ} \mathrm{C}$; colocação de telas em todas as janelas; pintura seriada dos boxes, e abertura de uma porta externa para acesso dos pacientes ao isolamento. Salientamos que segundo FONSECA (1983) "a planta $f$ isica da CTI estará na dependência da sua funcionali- dade. É indispensável que se observem alguns pontos quanto a: temperatura e umidade do ambiente deverão ser mantidas, evitando-se mudanças bruscas através de instalação de sistema de climatização sem recirculação de ar e ainda que os pisos e paredes deverão ser de material lavável, liso, não absorvente". Com o laboratório firmamos rotina da realização padronizada de culturas ambientais de 3 em 3 meses. Frente a administrão solicitamos a compra rotineira de fenol sintético para desinfecção da unidade; saco plástico para acondicionamento adequado do lixo; papel laminado para proteção dos painéis, e uma cama tipo beliche para o estar de enfermagem. Paralelamente a todas estas atividades realizamos treinamento em serviço das zeladoras com relação ao uso adequado dos desinfectantes ambientais e rotina de desinfecção em UTI.

Identificamos os riscos pertinentes aos clientes que freqüentemente são admitidos em estudo e as conseqüentes medidas de proteção específica traçadas. Ainda tendo como base a observação salientando a ro tina de admissão em UTI, notamos que nossa clientela proveniente do Pronto Socorro, Centro Cirúrgico ou Ala de Internamento eram críticos, muitas vezes com processo infeccioso ou susceptível aos mesmos, que utilizavam ou passavam a utilizar na UTI antibióticos potentes, e eram com freqüência submetidos a procedimentos invasivos. A inexistência de material suficiente para uso individualizado dos pacientes e a utilização do carro de curativo com mercuriais foram outros fatores de risco identificados por nós durante a observação in locus.

Com base nesta observação trabalhamos especificamente com a equipe intensivista, realizando uma seleção real dos pacientes, relacionando com patologias e procedimentos, dando ênfase às indicações de isolamento; passamos a controlar rigorosamente o antibiótico prescrito, adequando sempre aos resultados das culturas e antibiograma; as 'técnicas assépticas foram rigorosamente padronizadas, com gráfico de controle de trocas e monitorização das culturas dos cateteres e secreções. E como firma KFOURI (1985) "o antibiótico deverá ser escolhido sempre que possível de acordo com os testes de sensibilidade". Acionamos ainda a administração no sentido da compra de materiais, (bingo, aparadeiras, bacias, etc.), recebendo assim o suficiente para o uso individualizado, passando por processo de desinf ecção diária e esterilização semanal. Padronizamos o uso de bande jas individuais de curativos e uso de solução de PVPI, afastando assim definitivamente o uso do carro de curativo e mercuriais.

Foram identificados vários fatores de risco relacionando com a equipe multiprofissional e às medidas de proteção específicas traçadas. Partimos da avaliação do questionário aplicado e observaçãao de cotidiano, onde detectamos que nossa equipe apresentava vários vícios ou hábitos com relação a assistência aos pacientes críticos e durante a execução dos procedimentos e, ainda, que nunca tinham trabalhado em uma unidade com sistematização da assistência de enfermagem e utilização do plano de cuidado de enfermagem diário. Outras falhas detectadas eram a resistência no sentido do uso do uniforme privativo, a falta do hábito de lavar as mãos antes e depois da realização dos procedimentos, a escala sem rodízio e com jornadas ininterruptas; realização freqüente de Raio X onde, muitas 
vezes, o técnico solicitava à equipe para ajudar no posicionamento do paciente.

Com todos os dados acima relatados partimos para traçar um trabalho com metas específicas, procurando sempre justificar o porque dos nossos atos, tendo como ponta de apoio o embasamento científico. Planejamos um treinamento em serviço dado por todos os enfermeiros lotados na UTI, com cronograma específico, baseado nas patologias e procedimentos característicos e freqüentes nesta unidade, onde paralelamente realizávamos uma educação continuada sempre que admitíamos um novo paciente ou rea íź́vamos um procedimento. Utilizamos rotineiramente o plano de cuidado de enfermagem diário com ênfase na patologia básica, procedimentos, terapêutica medicamentosa e satisfação das necessidades básicas. Este funcionou como suporte na realização do nosso trabalho, pois ocorreu muita resistência de toda equipe intensivista no sentido de aceitar a prescrição de enfermagem, porém conseguimos introduzir com sucesso esta rotina. No sentido de evitar infecção cruzada e até mesmo da equipe adquiri-la padronizamos a utilização de roupa privativa e incentivamos a realização rotineira da lavagem das mãos através do exemplo, orientação e colocação de cartazes. Com o objetivo de minimizar os riscos ocupacionais ainda procuramos realizar rodízio mensal nas escalas de atribuições, dando ênfase a resistência medicamentosa e permanência com pacientes potencialmente contaminados. Com relação a escala de revesamento procuramos evitar jornadas ininterruptas de trabalho, visando diminuir os funcionários susceptíveis a acidentes do trabalho.

Acionamos ainda o serviço de Raio X no sentido de ter um auxiliar do técnico de Raio X para posicionar o paciente, devidamente protegido, como também o serviço médico da UTI, para limitação deste procedimento de acordo com a necessidade real, e ainda orientamos a equipe para manter-se distante durante o procedimento.

Segundo CANSIAN (1977) o uso de isotopos radiativos podem afetar a resistência orgânica do paciente, deprimindo a medula, reduzindo a produção de granulócitos e macrofagos; esta terapêutica inibe o sistema retículo-endotelial, deprime a síntese de imunoglobulinas; podem promover alterações cromossomiais nos leucócitos e alterar proteínas já sintetizadas, modificando suas propriedades". E ROCHA (1987) citando AL ARA diz que "as doses de radiação para os trabalhadores e também para o público devem ser em qualquer atividade onde haja exposições as radiações, somado os esforços para que a dose recebida seja a menor possível".

Queremos salientar que os riscos detectados e a proteção específica tem como objetivo real tanto o paciente como a equipe intensivista. Sentimos como limitação a inexistência de uma bibliografia que relatasse os riscos ocupacionais em UTI. O trabalho nos fez refletir frente aos problemas, e descobrimos que os riscos relacionados com a equipe estão muito interrelacionados com os riscos dos pacientes e que tudo que foi planejado tentando minimizar os riscos ocupacionais na unidade, tiveram ef eitos relevantes frente ao controle de infecção hospitalar em UTI, e com certeza proteção específica para o paciente.

\section{CONCLUSÃO}

$\mathrm{Na}$ unidade de Terapia Intensiva existem, como acabamos de descrever os riscos eminentes para todos que estão presentes no ambiente, mas estamos preocupados em aprimorar nossos conhecimentos e trabalhar para que estes riscos tornem-se cada vez menores. Estamos cientes, porém, que eles sempre existirão, visto que se trata de uma unidade que concentra pacientes de patologias diversas confinados em um ambiente em uso na maioria das vezes de procedimentos críticos.

Quando nos propomos a estudar os riscos ocupacionais estávamos convencidas que toda a problemática não estava somente no paciente e sim no próprio ambiente e naqueles que de uma forma ou de outra prestavam assistência aos pacientes. Logo o interrelacionamento entre o trinômio ambiente/paciente e equipe intensivista era real. Utilizando-se de medidas específicas de proteção na UTI procuramos de certa forma minimizar os riscos detectados. Finalmente como profissionais liberais não podemos agir de forma imatura ou impensada e nos organizamos, fizemos alterações na planta física, traçamos fluxogramas, im plantamos rotinas e normas, educação e sistematização da assistência de enfermagem. Enfatizamos o trabalho em equipe e o apoio encontrado na direção e dos serviços auxiliares. No entanto salientamos que nossa luta continua, devemos lutar por um ambiente que não nos agrida, por melhores condições de trabalho e não por percentagens, que de certo, não serão suficientes para tratar uma inf ecção.

\section{REFERÊNCIAS BIBLIOGRÁFICAS}

1 BRASIL, Ministerio da Saúde. Manual de Controle de Infecção Hospitalar, Brasília, 1985.

2 CANSIAN, T. M. A Enfermagem e o Controle de Infecção Cruzada. Rev. Bras. Enf. DF, 30:412-422, 1977.

3 CASTRO, Ione de Souza. Manual de Enfermagem em CTI. Rio de Janeiro. Cultura Médica, 1988.

4 ELHART, Doroth et alii. Princípios Científicos de Enfermagem, 8. ed., Lisboa, Ed. Portuguesa de Livros Técnicos e Científicos, 1983.

5 FONSECA, Maria Adelaide Q. et alii. Enfermagem em Centro de Tratamento Intensivo, 2. ed., São Paulo, Livraria Atheneu, 1983.

6 FREITAS, F. M. Infecção Respiratória como Complicação em Pacientes Neurologicos na UTI. Irmandade de Santa Casa de Londrina, nov. 1987, mimeogr.

7 KFOURI, Filho M. Atribuição da Farmácia Hospitalar na Comissão de Controle de Infecção Hospitalar. Revista Paulista de Enf., São Paulo, 5(4):145-149, out. dez. 1985.

8 LOLA, Maria Jurandy F. O Ambiente da Enfermaria atuando como fator terrapêutico. João Pessoa, Ed. Universitária/UFPb, 1984.

9 ROCHA, Sonia F. Assistência de Enfermagem ao paciente irradiado - Procedimentos em acidentes com radiação, nov. 1987, mimeogr.

10 SANTOS, E. et alii. Atuação da Enfermeira no Controle de Infecção em Unidade de Terapia Intensiva. Rev. Brasileira de Enf., DF. 33:369-376, 1980.

11 SILVA, Maria d'Apparecida A. et alii. Enfermagem na Unidade de Centro Cirúrgico. São Paulo, EPU, 1982. 